\title{
Family average income and body mass index above the healthy weight range among urban and rural residents in regional Mainland China
}

\author{
Fei $\mathrm{Xu}^{1, *}$, Xiao-Mei Yin ${ }^{1}$, Min Zhang ${ }^{1}$, Eva Leslie ${ }^{2}$, Robert Ware ${ }^{3}$ and Neville Owen ${ }^{2}$ \\ ${ }^{1}$ Nanjing Municipal Center for Disease Control \& Prevention, 2 Zizhulin, Nanjing 210003, People's Republic of \\ China: ${ }^{2}$ Cancer Prevention Research Center, The University of Queensland, Australia: ${ }^{3}$ School of Population Health, \\ The University of Queensland, Australia
}

Submitted 2 March 2004: Accepted 30 June 2004

\begin{abstract}
Objective: To explore the relationship between family average income (FAI; an index of socio-economic status) and body mass index (BMI; a widely used, inexpensive indicator of weight status) above the healthy weight range in a region of Mainland China.

Design: Population-based cross-sectional study, conducted between October 1999 and March 2000 on a sample of regular local residents aged 35 years or older who were selected by random cluster sampling.

Setting: Forty-five administrative villages selected from three urban districts and two rural counties of Nanjing municipality, Mainland China, with a regional population of 5.6 million.

Subjects: In total, 29340 subjects participated; $67.7 \%$ from urban and $32.3 \%$ from rural areas; $49.8 \%$ male and $50.2 \%$ female. The response rate among eligible participants was $90.1 \%$.

Results: The proportion of participants classified as overweight was 30.5\%, while $7.8 \%$ were identified as obese. After adjusting for possible confounding variables (age, gender, area of residence, educational level, occupational and leisure-time physical activity, daily vegetable consumption and frequency of red meat intake), urban participants were more likely to be overweight or obese relative to their rural counterparts, more women than men were obese, and participants in the lowest FAI tertile were the least likely to be above the healthy weight range.

Conclusions: The proportion of adults with BMI above the healthy weight range was positively related to having a higher socio-economic status (indexed by FAI) in a regional Chinese population.
\end{abstract}

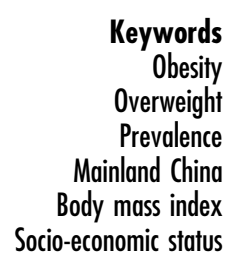

The proportion of overweight and obese adults is increasing at an alarming rate world-wide ${ }^{1-9}$. There is evidence that being overweight or obese leads to adverse metabolic effects on blood pressure, cholesterol, triglycerides and insulin resistance $\mathrm{e}^{10-12}$.

A sedentary lifestyle and poor diet are strongly associated with obesity ${ }^{13-18}$. Socio-economic status (SES) is a risk marker for such lifestyle behaviours. SES is negatively associated with overweight and obesity in developed societies ${ }^{19-25}$ and positively associated in developing countries ${ }^{26,27}$. Because SES is a complex construct, the different variables used to measure it provide different information on participants' relative socio-economic position within their community and can reflect different specific exposures ${ }^{28}$. In this study, we developed family average income per capita (FAI) as a new and specific index of SES. This may have utility as a single measure of SES since it may be a more realistic reflection of material measures and social standing than other indicators such as educational attainment, occupation, total household income or deprivation score ${ }^{29}$. Income is a direct (although incomplete) measure of economic resources. However, total household income does not reflect income per capita in families because, with the same household income, a larger family will have different life quality from a smaller family. Although education and occupation partially determine a participant's adult SES, in areas such as Mainland China where the economy is undergoing a rapid transition, the relationship may be of less value than in a more settled economy as people are in a position to change occupation more readily.

With the economy growing rapidly in China, there is an increasing transition within the population towards more 
Westernised behaviour patterns ${ }^{30}$. Diseases related to being overweight are becoming increasingly burdensome and present urgent public health challenges ${ }^{30}$, and preventive strategies are required. In this context, it is important to explore the relationship between SES and overweight in China. In the present paper, we examine the associations of SES with body mass index (BMI) using data obtained through a large populationbased survey conducted in both urban and rural areas of regional Mainland China between October 1999 and March 2000.

\section{Methods}

\section{Sample selection}

A large-scale, population-based, cross-sectional study was conducted in Nanjing municipality. Nanjing, the capital of Jiangsu province, is located in the east of China and has a population of more than 5.6 million. It has 15 administrative units, 10 urban and five rural. Sampling was undertaken using a multi-stage method. First, we randomly selected three urban districts and two rural counties, then three streets/towns from each chosen district/county. Finally, three administrative villages in each street/town were randomly selected. This resulted in a total number of 45 villages. To be eligible for inclusion in the study, participants had to be aged 35 years or more and have been a local resident for at least 5 years.

\section{Questionnaire and definitions}

The questionnaire was administrated by household interview. It included questions on age, gender, the number of family members, total monthly income of the family, body weight and height, and other basic demographic information.

Participants, wearing light indoor clothing and without shoes, had their weight measured to the nearest $100 \mathrm{~g}$ using a beam balance scale, and their height measured to the nearest millimetre using a stadiometer. Weight and height were measured twice and the mean value of the readings was used for the analysis. BMI was calculated by dividing weight $(\mathrm{kg})$ by the square of height $(\mathrm{m})$. Participants with BMI of $24 \mathrm{~kg} \mathrm{~m}^{-2}$ or greater were classed as being above the healthy weight range, and categorised as overweight (BMI between 24 and $28 \mathrm{~kg} \mathrm{~m}^{-2}$ ) or obese (BMI greater than $\left.28 \mathrm{~kg} \mathrm{~m}^{-2}\right)^{11,31}$.

A family was defined as those who lived together and shared living-related expenditures. The total monthly income of all family members is the monthly total earnings of the whole family; including salaries, pensions and allowances, money from selling goods and products, and the estimated market-price value of products for personal/family consumption. Family average income (FAI), the average total monthly income of all family members, was divided into tertiles to derive three categories: lower, middle and higher. Previously reported predictors of obesity in adults assessed were age, gender, educational attainment, sedentary lifestyle and poor diet $^{13-27}$. These covariates were also reported to be predictors of obesity in Chinese adults ${ }^{32}$, so we chose age, gender, area of residence (rural or urban), educational attainment ( $0-9$ years; $10-12$ years; 13 years or more), occupational physical activity (classified as 'light' receptionist, office worker, assembly worker; 'moderate' - repairer, electrician, machinist; or 'vigorous' - farmer, steel-maker, lumberman), leisure-time physical activity (classified as 'light' - cooking, flower-growing, watching television; 'moderate' - jogging, dancing, Chinese Taiji; 'vigorous' - ball sports, field-running), amount of vegetable consumption ('low' $-<100 \mathrm{~g} \mathrm{day}^{-1}$; 'moderate' - 100-500 $\mathrm{g} \mathrm{day}^{-1}$; 'high' - > $500 \mathrm{~g} \mathrm{day}^{-1}$ ) and frequency of red meat consumption ('low' $-<6$ times/week; 'moderate' - 6-18 times/week; 'high' - >18 times/week) as the covariates in the analysis.

\section{Data management and analysis}

This survey was conducted by health-care professionals who were trained in correct interview procedures prior to survey administration. The data were double-entered and cleaned via Epi Info 6.04 (Centers for Disease Control and Prevention, Atlanta, GA, USA), and managed and analysed via SPSS version 10.0 (SPSS Inc., Chicago, IL, USA). Demographic variables were compared across FAI tertiles via odds ratios.

\section{Results}

The total number of survey respondents was 29353. The response rate was $90.1 \%$, with no significant demographic difference between responders and non-responders. There were $67.7 \%$ urban and $32.3 \%$ rural residents; $49.8 \%$ were male and $50.2 \%$ female. Table 1 shows demographic characteristics of the sample participants with different FAI in this study.

The proportion of participants identified as having BMI above the healthy weight range was $38.2 \%$; 30.5\% were overweight and $7.8 \%$ obese. Table 2 presents the prevalence of overweight and obese adults by main covariates.

After adjusting for age, gender, educational level, occupational and leisure-time physical activity, daily vegetable consumption and frequency of red meat intake, urban residents were more likely to be both overweight (odds ratio (OR) 1.74, 95\% confidence interval (CI) 1.611.88) and obese (OR 3.23, 95\% CI 2.79-3.73) than their rural counterparts.

Table 3 presents data on proportions above the healthy weight range within categories of FAI by area of residence and gender. It shows that women were more likely than men to be obese, and that participants in the lower FAI tertile were less likely to be overweight or obese than participants in the upper two FAI tertiles. 
Table 1 Demographic characteristics of the sample participants with different family average income (FAl) in regional Mainland China

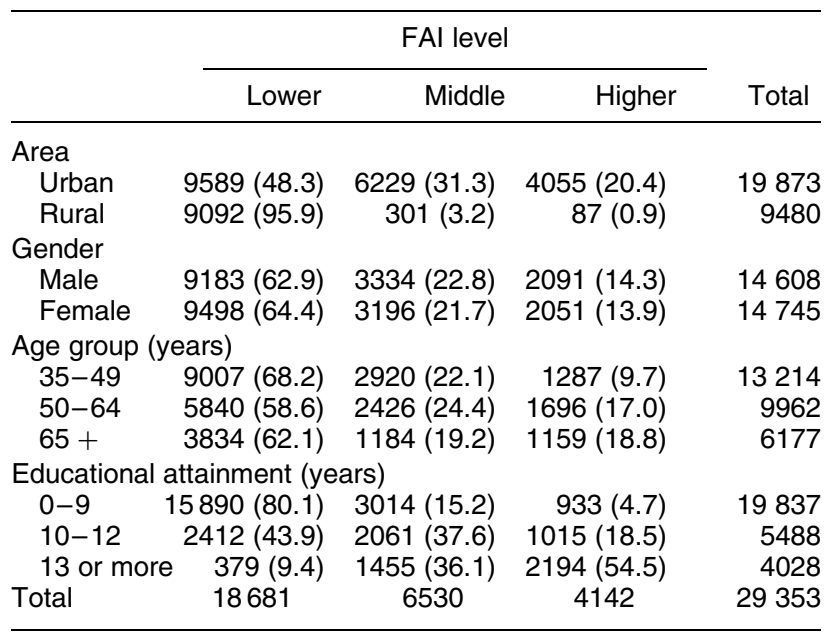

Values are expressed as $n(\%)$, where $n$ is the number of participants within each subgroup and $\%$ is the percentage of participants within each subgroup.

Table 4 shows that, in all three categories, middle-aged participants were more likely to be overweight or obese. Participants in the lowest FAI stratum were the least likely to be above the healthy weight range, for each age group.

\section{Discussion}

In this study, our focus was on the relationship between SES (defined by FAI) and BMI above the healthy weight range in the context of Mainland China. The overall prevalence of obesity in Mainland China was lower than

Table 2 Prevalence of overweight and obese adults by main covariates in Mainland China

\begin{tabular}{lll}
\hline Covariate & \multicolumn{1}{c}{ Overweight } & \multicolumn{1}{c}{ Obese } \\
\hline Educational attainment (years) & \\
$0-9$ & $29.3(5817 / 19839)$ & $8.2(1620 / 19839)$ \\
$10-12$ & $32.1(1759 / 5488)$ & $7.7(420 / 5488)$ \\
13 years & $34.4(1383 / 4026)$ & $6.3(255 / 4026)$ \\
Occupational physical activity & \\
Light & $32.0(6418 / 20071)$ & $8.7(1750 / 20071)$ \\
Moderate & $32.3(969 / 3004)$ & $7.1(212 / 3004)$ \\
Vigorous & $25.0(1572 / 6278)$ & $5.3(333 / 6278)$ \\
Leisure-time physical activity & \\
Light & $30.6(7253 / 23700)$ & $8.3(1963 / 23700)$ \\
Moderate & $30.5(1574 / 5155)$ & $6.0(309 / 5155)$ \\
Vigorous & $26.5(132 / 498)$ & $4.6(23 / 498)$ \\
Amount of vegetable consumption & \\
Light & $29.7(461 / 1550)$ & $7.0(108 / 1550)$ \\
Moderate & $30.4(4696 / 15424)$ & $7.7(1189 / 15424)$ \\
High & $30.7(3802 / 12379)$ & $8.1(998 / 12379)$ \\
Frequency of red meat consumption & \\
Light & $24.7(1610 / 6513)$ & $6.8(444 / 6513)$ \\
Moderate & $30.1(3547 / 11797)$ & $7.4(868 / 11797)$ \\
High & $34.4(3802 / 11043)$ & $8.9(983 / 11043)$ \\
\hline
\end{tabular}

Values are expressed as \% $(n / N)$, where \% is the percentage of overweight/obese participants, $n$ is the number of overweight/obese participants and $N$ is the total number participants within the subgroup. the figures reported for developed countries, but higher than has been reported for Malaysia and Cameroon ${ }^{2-8}$. The proportion of participants categorised as being above the healthy weight range (38.2\%) in our study was similar to that documented in a national report from China ${ }^{30}$. We found that urban people were more likely to be overweight and obese, men were less likely to be obese than women, and participants in the lower FAI category were the least likely to be above the healthy weight range. Our findings are consistent with other studies that show positive associations between higher SES and obesity in developing countries ${ }^{26,27}$.

There was no significant association between FAI categories and being above the healthy weight range in urban areas. However, in rural areas, participants in the lower FAI category were less likely to be above the healthy weight range than were participants in the higher and middle FAI categories. This may be explained by lifestyle and behaviour patterns that tend to be much more Westernised in urban areas and may affect all social groups, more so than in the rural areas in China ${ }^{30}$.

Women were more likely to be above the healthy weight range relative to men in the lower FAI tertile, but were less likely to be above the healthy weight range relative to men in both higher and middle FAI categories. One possible explanation for this phenomenon is that, for men within the higher and middle categories of SES, it is culturally more acceptable to adopt Western lifestyles and behaviour patterns (such as eating out and consuming alcohol) than it is for women in China.

A limitation of the study is that family average incomes were self-reported. Participants may have underestimated their earnings and the value of home-grown foods and informal barter arrangements that are common practice in rural areas. Another limitation is that some $9.9 \%$ of eligible subjects were not interviewed. These people were mostly young men in rural areas, who had temporarily vacated their permanent residence to undertake casual work. The proportion of overweight adults in this group is relatively low, so the general prevalence may be overestimated in this regional population. While it is possible that more than one participant may have come from the same household, the data did not identify this so it was not possible to control for clustering in the analyses.

More studies, especially with prospective designs, that examine such factors need to be conducted to explore the relationship between SES and the likelihood of being overweight or obese under different circumstances in countries undergoing demographic and epidemiological transitions such as those currently taking place in Mainland China.

\section{Conclusions}

The proportion of adults with BMI above the healthy weight range was positively related to SES in the current 
Table 3 Prevalence of overweight and obese adults by area of residence and gender, within family average income (FAl) categories in Mainland China

\begin{tabular}{|c|c|c|c|c|c|}
\hline \multirow[b]{2}{*}{ FAl level } & & \multicolumn{2}{|c|}{ Overweight } & \multicolumn{2}{|c|}{ Obese } \\
\hline & & Prevalence & $\begin{array}{l}\text { Adjusted OR } \\
\qquad(95 \% \mathrm{Cl})\end{array}$ & Prevalence & $\begin{array}{l}\text { Adjusted OR } \\
(95 \% \mathrm{Cl})\end{array}$ \\
\hline \multicolumn{6}{|l|}{ Overall } \\
\hline All levels & & $30.5(8959 / 29353)$ & & $7.8(2295 / 29353)$ & \\
\hline Lower & & $27.8(5201 / 18681)$ & 1.00 & $7.3(1358 / 18681)$ & 1.00 \\
\hline Middle & & $35.1(2295 / 6530)$ & $1.14(1.06-1.22)$ & $9.1(598 / 6530)$ & $0.999(0.89-1.12)$ \\
\hline Higher & & $35.3(1463 / 4142)$ & $1.17(1.07-1.28)$ & $8.2(339 / 4142)$ & $0.96(0.82-1.12)$ \\
\hline \multicolumn{6}{|l|}{ Area } \\
\hline \multirow[t]{2}{*}{ All levels } & Rural & $22.0(2086 / 9480)$ & 1.00 & $3.8(357 / 9480)$ & 1.00 \\
\hline & Urban & $34.5(6854 / 19873)$ & $1.74(1.61-1.88)$ & $9.7(1928 / 19873)$ & $3.23(2.79-3.73)$ \\
\hline \multirow[t]{2}{*}{ Lower } & Rural & $21.6(1960 / 9092)$ & 1.00 & $3.8(343 / 9092)$ & 1.00 \\
\hline & Urban & $33.6(3225 / 9589)$ & 1.76 (1.62-1.92) & $10.5(1009 / 9589)$ & $2.92(2.50-3.41)$ \\
\hline \multirow[t]{2}{*}{ Middle } & Rural & $32.2(97 / 301)$ & 1.00 & $3.7(11 / 301)$ & 1.00 \\
\hline & Urban & $35.3(2198 / 6229)$ & $1.09(0.82-1.44)$ & $9.4(584 / 6229)$ & 4.59 (2.33-9.05) \\
\hline \multirow{2}{*}{ Higher } & Rural & $33.3(29 / 87)$ & 1.00 & $3.4(3 / 87)$ & 1.00 \\
\hline & Urban & $35.3(1431 / 4055)$ & $1.15(0.70-1.91)$ & $8.3(335 / 4055)$ & $3.42(1.02-11.55)$ \\
\hline \multicolumn{6}{|l|}{ Gender } \\
\hline \multirow[t]{2}{*}{ All levels } & Female & $30.9(4553 / 14745)$ & 1.00 & $9.0(1332 / 14745)$ & 1.00 \\
\hline & Male & $30.0(4387 / 14608)$ & $0.95(0.90-0.99)$ & $6.5(953 / 14608)$ & $0.73(0.67-0.80)$ \\
\hline \multirow[t]{2}{*}{ Lower } & Female & $30.0(2845 / 9498)$ & 1.00 & $8.9(846 / 9498)$ & 1.00 \\
\hline & Male & $25.5(2340 / 9183)$ & $0.78(0.73-0.83)$ & $5.5(506 / 9183)$ & $0.60(0.53-0.67)$ \\
\hline \multirow[t]{2}{*}{ Middle } & Female & $32.9(1050 / 3196)$ & 1.00 & $9.9(315 / 3196)$ & 1.00 \\
\hline & Male & $37.3(1245 / 3334)$ & $1.24(1.11-1.38)$ & $8.4(280 / 3334)$ & $0.97(0.81-1.17)$ \\
\hline \multirow[t]{2}{*}{ Higher } & Female & $32.1(658 / 2051)$ & 1.00 & $8.3(171 / 2051)$ & 1.00 \\
\hline & Male & $38.4(802 / 2091)$ & $1.34(1.17-1.53)$ & $8.0(167 / 2091)$ & $0.98(0.77-1.23)$ \\
\hline
\end{tabular}

OR - odds ratio; $\mathrm{Cl}$ - confidence interval.

Prevalence values are expressed as $\%(n / M)$, where $\%$ is the percentage of overweight/obese participants, $n$ is the number of overweight/ obese participants and $N$ is the total number of participants within the subgroup.

Table 4 Prevalence of overweight and obese adults by age, within family average income (FAI) categories in Mainland China

\begin{tabular}{|c|c|c|c|c|c|}
\hline \multirow[b]{2}{*}{ FAl level } & \multirow[b]{2}{*}{ Age (years) } & \multicolumn{2}{|c|}{ Overweight } & \multicolumn{2}{|c|}{ Obese } \\
\hline & & Prevalence & $\begin{array}{c}\text { Adjusted OR } \\
(95 \% \mathrm{Cl})\end{array}$ & Prevalence & $\begin{array}{l}\text { Adjusted OR } \\
(95 \% \mathrm{Cl})\end{array}$ \\
\hline \multirow[t]{3}{*}{ Overall } & $35-49$ & $29.5(3892 / 13214)$ & 1.00 & $6.2(824 / 13214)$ & 1.00 \\
\hline & $50-64$ & $34.1(3395 / 9962)$ & $1.21(1.14-1.28)$ & $9.1(906 / 9962)$ & $1.48(1.33-1.64)$ \\
\hline & $65+$ & $36.8(1653 / 6177)$ & $0.86(0.80-0.93)$ & $9.0(555 / 6177)$ & $1.42(1.26-1.61)$ \\
\hline \multirow[t]{3}{*}{ Lower } & $35-49$ & $28.6(2578 / 9007)$ & 1.00 & $6.3(565 / 9007)$ & 1.00 \\
\hline & $50-64$ & $30.2(1765 / 5840)$ & $1.13(1.05-1.22)$ & $8.5(497 / 5840)$ & $1.43(1.25-1.63)$ \\
\hline & $65+$ & $22.0(842 / 3834)$ & $0.70(0.64-0.78)$ & $7.6(290 / 3834)$ & $1.22(1.04-1.44)$ \\
\hline \multirow[t]{3}{*}{ Middle } & $35-49$ & $31.7(926 / 2920)$ & 1.00 & $6.4(187 / 2920)$ & 1.00 \\
\hline & $50-64$ & $39.4(955 / 2426)$ & $1.34(1.19-1.51)$ & $10.8(262 / 2426)$ & $1.61(1.31-1.98)$ \\
\hline & $65+$ & $35.0(414 / 1184)$ & $1.10(0.94-1.29)$ & $12.3(146 / 1184)$ & $1.67(1.30-2.15)$ \\
\hline \multirow[t]{3}{*}{ Upper } & $35-49$ & $30.1(388 / 1287)$ & 1.00 & $5.6(72 / 1287)$ & 1.00 \\
\hline & $50-64$ & $39.8(675 / 1696)$ & $1.46(1.25-1.71)$ & $8.7(147 / 1696)$ & $1.61(1.19-2.18)$ \\
\hline & $65+$ & $34.3(397 / 1159)$ & $1.21(1.02-1.45)$ & $10.3(119 / 1159)$ & $1.82(1.32-2.51)$ \\
\hline
\end{tabular}

OR - odds ratio; $\mathrm{Cl}$ - confidence interval.

Prevalence values are expressed as $\%(n / M)$, where \% is the percentage of overweight/obese participants, $n$ is the number of overweight/ obese participants and $N$ is the total number of participants within the subgroup.

Chinese context at the population level. People in the lower SES category were less likely to be above the healthy weight range, irrespective of their gender and age. In urban areas, no significant differences were detected for the proportions of adults with weight above the healthy range between all three FAI categories; in rural areas, participants in the lower FAI category were less likely to have BMI above the healthy weight range.

Observed associations between overweight/obesity and SES are consistent with other effects of epidemiological transition and identify a need for preventive initiatives.

\section{Acknowledgements}

We are most grateful to Nanjing Municipal Department of Health for its generous financial support of this study. We extend special thanks to the following for their support of the study: Xunwu District, Jianye District, Dachang District, Jiangpu County and Gaochun County Department of Health; Jiangsu Provincial, Xunwu District, Jianye District, Dachang District, Jiangpu County and Gaochun County Center for Disease Control \& Prevention; as well as all workers and investigators involved. 


\section{References}

1 World Health Organization (WHO). Obesity: Preventing and Managing the Global Epidemic. Report of a WHO Consultation on Obesity. Geneva: WHO, 1997.

2 King GA, Fitzhugh EC, Bassett DR Jr, McLaughlin JE, Strath SJ, Swartz AM, et al. Relationship of leisure-time physical activity and occupational activity to the prevalence of obesity. International Journal of Obesity 2001; 25: 606-12.

3 Katzmarzyk PT. The Canadian obesity epidemic, 1985-1998. Canadian Medical Association Journal 2002; 166(8): 1039-40.

4 McCarthy SN, Gibney MJ, Flynn A. Overweight, obesity and physical activity levels in Irish adults: evidence from the North/South Ireland food consumption survey. Proceedings of the Nutrition Society 2002; 61: 3-7.

5 Stam-Moraga MC, Kolanowski J, Dramaix M, De Backer G, Kornitzer MD. Sociodemographic and nutritional determinants of obesity in Belgium. International Journal of Obesity and Related Metabolic Disorders 1999; 23(Suppl. 1): 1-9.

6 Australian Bureau of Statistics (ABS). Department of Health and Family Services. National Nutrition Survey: Selected Highlights 1995. Canberra: ABS \& Department of Health and Family Services, 1997.

7 Ismail MN, Chee SS, Nawawi H, Yusoff K, Lim TO, James WP. Obesity in Malaysia. Obesity Reviews 2002; 3: 203-8.

8 Wang WJ, Wang KA, Li TL, Xiang HD, Ma LM, Fu ZY, et al. Obesity epidemic patterns of Chinese adults: prevalence survey of overweight and obesity. Chinese Journal of Epidemiology 2001; 22: 129-32.

9 Sinewy E, Mbanya JC, Unwin NC, Kengne AP, Fezeu L, Minkoulou EM, et al. Physical activity and its relationship with obesity, hypertension and diabetes in urban and rural Cameroon. International Journal of Obesity and Related Metabolic Disorders 2002; 26: 1009-16.

10 Mokdad AH, Ford ES, Bowman BA, Dietz WH, Vinicor F, Bales VS, et al. Prevalence of obesity, diabetes, and obesityrelated health risk factors, 2001. Journal of the American Medical Association 2003; 289: 76-9.

11 Cooperative Meta-analysis Group of China Obesity Task Force. Predictive values of body mass index and waist circumference to risk factors of related diseases in Chinese adult population. Chinese Journal of Epidemiology 2002; 23: 5-10.

12 World Health Organization (WHO). Reducing Risks, Promoting Healthy Life. The World Health Report 2002. Geneva: WHO, 2002.

13 Mokdad AH, Bowman BA, Ford ES, Vinicor F, Marks JS, Koplan JP. The continuing epidemics of obesity and diabetes in the United States. Journal of the American Medical Association 2001; 286: 1195-200.

14 Robinson TN. Reducing children's television viewing to prevent obesity: a randomized controlled trial. Journal of the American Medical Association 1999; 282: 1561-7.

15 Salmon J, Bauman A, Crawford D, Timperio A, Owen N. The association between television viewing and overweight among Australian adults participating in varying levels of leisure-time physical activity. International Journal of Obesity and Related Metabolic Disorders 2000; 24: 600-6.

16 Chen M, You Y, Zhao W, Yang X. Influences of diet and nutrition on obesity of pre-school children. Health Research 2003; 31: 370-2

17 Astrup A. Healthy lifestyles in Europe: prevention of obesity and type II diabetes by diet and physical activity. Public Health Nutrition 2001; 4(2B): 499-515.

18 Shepard TY, Weil KM, Sharp TA, Grunwald GK, Bell ML, Hill $\mathrm{JO}$, et al. Occasional physical inactivity combined with a high-fat diet may be important in the development and maintenance of obesity in human subjects. American Journal of Clinical Nutrition 2001; 73: 703-8.

19 Wardle J, Waller J, Jarvis MJ. Sex difference in the association of socioeconomic status with obesity. American Journal of Public Health 2002; 92: 1299-304.

20 Ball K, Mishra G, Crawford D. Which aspects of socioeconomic status are related to obesity among men and women? International Journal of Obesity and Related Metabolic Disorders 2002; 26: 559-65.

21 Everson SA, Maty SC, Lynch JW, Kaplan GA. Epidemiologic evidence for the relation between socioeconomic status and depression, obesity, and diabetes. Journal of Psychosomatic Research 2002; 53: 891-5.

22 Moore DB, Howell PB, Treiber FA. Changes in overweight in youth over a period of 7 years: impact of ethnicity, gender and socioeconomic status. Ethnicity \& Disease 2002; 12(Suppl. 1): 83-6.

23 Gnavi R, Spagnoli TD, Galotto C, Pugliese E, Carta A, Cesari L. Socioeconomic status, overweight and obesity in prepuberal children: a study in an area of Northern Italy. European Journal of Epidemiology 2001; 16: 797-803.

24 Kaluski DN, Chinich A, Leventhal A, Ifrah A, CohenMannheim I, Merom D, et al. Overweight, stature, and socioeconomic status among women - cause or effect: Israel National Women's Health Interview Survey, 1998. Journal of Gender-Specific Medicine 2001; 4: 18-24.

25 De Spiegelaere M, Dramaix M, Hennart P. The influence of socioeconomic status on the evolution of obesity during early adolescence. International Journal of Obesity and Related Metabolic Disorders 1998; 22: 268-74.

26 Sobal J. Obesity and socioeconomic status: a framework for examining relationships between physical and social variables. Medical Anthropology 1992; 13: 231-47.

27 Sobal J, Stunkard AJ. Socioeconomic status and obesity: a review of the literature. Psychological Bulletin 1989; 105: 260-75.

28 Robbins JM, Vaccarino V, Zhang H, Kasl SV. Socioeconomic status and type 2 diabetes in African American and nonHispanic white women and men: evidence from the Third National Health and Nutrition Examination Survey. American Journal of Public Health 2001; 91: 76-83.

29 Connolly V, Unwin N, Sherriff P, Bilous R, Kelly W. Diabetes prevalence and socioeconomic status: a population based study showing increased prevalence of type 2 diabetes mellitus in deprived areas. Journal of Epidemiology and Community Health 2000; 54: 173-7.

30 Du S, Lu B, Zhai F, Popkin BM. A new stage of the nutrition transition in China. Public Health Nutrition 2002; 5(1A): 169-74.

31 Wang WJ, Wang KA, Li TL, Xiang HD, Ma LM, Fu ZY, et al. A discussion on utility and purposed value of obesity abdomen obesity when body mass index, waist circumference, waist to hip ratio used as indices hypertension and hyper blood glucose. Chinese Journal of Epidemiology 2002; 23: $16-9$.

32 Bell AC, Ge K, Popkin BM. Weight gain and its predictors in Chinese adults. International Journal of Obesity and Related Metabolic Disorders 2001; 25: 1079-86. 